\title{
COMORBIDITY IN PATIENTS WITH CHRONIC CORONARY SYNDROMES: PREVALENCE AND ASSESSMENT
}

D0I: $10.36740 /$ WLek202003110

\author{
Galina Z. Moroz, Irina M. Hidzynska, Anatoly M. Kravchenko, Tatyana S. Lasytsia, Olena 0. Dzizinska \\ STATE INSTITUTION OF SCIENCE"RESEARCH AND PRACTICAL CENTER OF PREVENTIVE AND CLINICAL MEDICINE"STATE ADMINISTRATIVE DEPARTMENT, \\ KYIV, UKRAINE
}

\begin{abstract}
The aim: To carry out an evaluation of comorbidities in CCS patients having undergone PCI for stable coronary artery diseases (planned) or PCl in myocardial infarction (urgent) with the aim of justifying the best management strategies.

Materials and methods: We carried out an analysis of comorbid pathology spreading and the evaluation of multiple comorbidities using of Combined Age Charlson Comorbidity Index (CA-C(I) - in 138 patients below 75 yrs having undergone urgent and planned PCI. These patients were divided into two groups; the $\mathrm{I}^{\text {st }}$ one included 60 patients with urgent $\mathrm{PCl}$ (angioplasty with stent), the $2^{\text {nd }}$ group -78 patients with planned $\mathrm{PCl}$.

Results: We found a high prevalence of comorbidity in CCS patients: the mean number of diseases in patients of the $1^{\text {st }}$ and $2^{\text {nd }}$ groups were $8.2 \pm 0.3$ and $9.3 \pm 0.4$, and the CA$\mathrm{CCl}$ values $-7.3 \pm 0.3$ and $7.5 \pm 0.2$, respectively $(\mathrm{p}>0.05)$. Ten and more diseases were found in $(28.3 \pm 5.8 \%)$ patients from the $1^{\text {st }}$ group and in $(43.6 \pm 5.6 \%)$ patients from the $2^{\text {nd }}$ group ( $\mathrm{p}=0.06$ ). The most frequent comorbidities were arterial hypertension, cerebrovascular diseases, peripheral arterial disease, type 2 diabetes mellitus, and impaired glucose metabolism.

Conclusions: Comprehensive assessment and management of patients with $C C S$ who undergo $\mathrm{PCI}$ remains a current problem in modern medicine, given the high prevalence of comorbid pathology.
\end{abstract}

KEY WORDS: chronic coronary syndromes, percutaneous coronary intervention, comorbidity, Charlson Comorbidity Index

Wiad Lek. 2020;73(3):462-465

\section{INTRODUCTION}

A prominent feature of modern medicine is its continuous process of improvement concerning current diagnostics and treatment approaches. According to the recently published "2019 ESC Guidelines for the Diagnosis and Management of Chronic Coronary Syndrome" [1] the term "stable coronary artery disease" was substituted by "chronic coronary syndrome" (CCS). The authors point out "the dynamic nature of the coronary artery disease (CAD) process results in various clinical presentations which can be conveniently categorized as either acute coronary syndromes or chronic coronary syndromes" [1]. According to the indications of these Guidelines, comorbidity assessment belongs to the most important requirements for the clinical evaluation of patient's health status. It should be taken into consideration that presence of several diseases needing medical interventions leads to the worsening of patient's condition, increased disability and functional decline, and, as a result, to worsened patient's quality of life and life expectancy $[2,3]$. Scientific researches having been carried out in different countries suggest the increasing amount of comorbidities in CAD patients $[4,5]$. The results of longitudinal studies show a positive correlations between comorbidity evaluated according to the Charlson Comorbidity Index (CCI) and the life span. Among CAD patients, the most unfavorable prognosis is found for pa- tients with type 2 diabetes mellitus, kidneys failure, chronic obstructive lung disease, and peripheral arterial disease [6]. Nowadays in clinical practice we can see an increasing number of $\mathrm{CAD}$ patients having undergone myocardial revascularization. There are here a lot of problems which are to be solved; consequently, the assessment of comorbid pathology spreading is an important one. In this study we carry out a combined evaluation of comorbidity in CCS patients after PCI for stable coronary artery diseases or PCI in myocardial infarction in order to justify the need for their management optimization.

\section{THE AIM}

To carry out an evaluation of comorbidities in CCS patients having undergone PCI for stable coronary artery diseases (planned) or PCI in myocardial infarction (urgent) with the aim of justifying the best management strategies.

\section{MATERIALS AND METHODS}

We performed a retrospective analysis of 138 electronic medical records of CCS patients under age 75 years having obtained their medical care at the State Institution of Sciences "Research and Practical Center of Preventive and Clinical Medicine" State Administrative Department. All 
patients underwent myocardial revascularization via PCI for CAD (planned PCI) or PCI in myocardial infarction (angioplasty with stent, urgent PCI). The patients were divided into two groups; the $1^{\text {st }}$ group includes 60 persons (45 males and 15females) having undergone urgent PCI (patients were included to the study in a year or later following revascularization); the $2^{\text {nd }}$ group includes 78 persons (59 males and 19 females) after planned PCI. All the patients had CCS (according to the "2019 ESC Guidelines for the Diagnosis and Management of Chronic Coronary Syndrome") [1]. Patient's age ranged from 34 to 75 years, the mean age of patients in the $1^{\text {st }}$ and $2^{\text {nd }}$ group did not differ significantly and was $(66.3 \pm 0.81)$ and $(67.5 \pm 0.73)$ years, respectively. We have determined the number of diseases according to medical records data and performed a calculation of multimorbidity indicators - CCI and Combined Age Charlson Comorbidity Index (CA-CCI) $[7,8]$. We used statistical software programs (Statistica v. 6.0) and Microsoft Excel 2007 applications for data analysis. Categorical data were presented as absolute and relative (\%) frequency. To enable comparisons, we calculated the mean value $(M)$, and the standard error of the mean $(m)$. Student's t-test was used to compare the mean of a data for the two groups.

\section{RESULTS}

According to data of the medical records the number of comorbid diseases in patients having been examined ranged from 3 to 12 . Ten and more diseases were detected in 17 patients among 60 ones $(28.3 \pm 5.8 \%)$ having undergone urgent PCI and in 34 patients among 78 persons $(43.6 \pm 5.6 \%)$ with planned ones $(\mathrm{p}=0.06)$. The majority of patients-46 in the $1^{\text {st }}(76.7 \pm 5.55 \%)$ and 67 in the $2^{\text {nd }}$ group $(85.9 \pm 3.9 \%)(\mathrm{p}=0.18)$ - had clinical manifestations of angina pectoris (class I or II according to the Canadian Cardiovascular Society grading scale for the classification of angina pectoris severity) [1].We found also both in the $1^{\text {st }}$ and the $2^{\text {nd }}$ groups a high prevalence of arterial hypertension - in 59 patients among 60 ones $(98.3 \pm 1.6 \%)$ and in 78 patients among 78 ones $(100 \%)$, respectively, cerebrovascular disease [in 45 persons among 60 ones $(75 \pm 5.6 \%)$ and in 69 patients among 78 ones $(88.5 \pm 3.6 \%)$, respectively, $\mathrm{p}=0.046$ ], atherosclerotic damage of retina vessels [in 39 patients among 60 ones $(65 \pm 6.2 \%)$ and in 52 patients among 78 ones $(66.7 \pm 5.3 \%)$, respectively, $\mathrm{p}=0.84$ ], peripheral arterial disease [in 19 patients among 60 ones $(31.7 \pm 6.0 \%)$ andin 38persons among 78 ones $(48.7 \pm 5.6 \%)$,respectively, $p=0.043$ ], and cardiac rhythm disturbance [in 20 patients among 60 ones $(33.3 \pm 6.1 \%)$ and in 23 patients among 78 ones $(29.5 \pm 5.2 \%)$, respectively, $\mathrm{p}=0.63$ ]. Heart failure NYHA Class I or II has been diagnosed in all the patients examined. Type 2 diabetes mellitus has been found in 13 patients among 60 ones $(21.7 \pm 5.3 \%)$ of the $1^{\text {st }}$ group and in 27 patients among 78 ones $(34.6 \pm 5.4 \%)$ of the $2^{\text {nd }}$ group $(\mathrm{p}=0.09) ; 24$ patients $(56.7 \% \pm 6.4 \%)$ of the $1^{\text {st }}$ group and 33 ones $(42.3 \pm 5.6 \%)$ of the $2^{\text {nd }}$ group, $\mathrm{p}=0.09$ had impaired glucose metabolism - namely impaired fasting glycaemia with fasting plasma glucose levels $\geq 5.6 \mathrm{mmol} / \mathrm{L}$. Renal disease has been diagnosed in 4 patients among 60 ones of the $1^{\text {st }}$ group $(6.7 \pm 3.2 \%)$ and in 8 patients of the $2^{\text {nd }}$ group $(10.3 \pm 3.4 \%), \mathrm{p}=0.45$.

Chronic cholecystitis and chronic pancreatitis were the most common disorders among digestive tract diseases in both groups: chronic cholecystitis has been registered in 19 patients of the $1^{\text {st }}$ group $(31.7 \pm 6.0 \%)$ and in 28 patients of the 2 nd group ( $35.9 \pm 5.4 \%), \mathrm{p}=0.61$, chronic pancreatitis - in 11 patients of the $1^{\text {st }}$ group $(18.3 \pm 5.0 \%)$ and in 26 patients of the 2nd group ( $33.3 \pm 5.3 \%), \mathrm{p}=0.04$.

Osteochondrosis is found to be a rather frequent disorder of musculoskeletal system being found in 26 patients among 60 ones $(43.3 \pm 6.4 \%)$ in the $1^{\text {st }}$ group and in $42 \mathrm{pa}-$ tients among 78 ones $(53.8 \pm 5.6 \%)$ in the $2^{\text {nd }}$ group, $\mathrm{p}=0.22$. Osteoarthrosis was detected in 10 patients among 60 ones $(16.7 \pm 4.8 \%)$ of the $1^{\text {st }}$ group and in 23 patients among 78 ones $(29.5 \pm 5.2 \%)$ of the $2^{\text {nd }}$ group, $p=0.07$. Cancer (any malignancy, including malignant neoplasm of the skin) were diagnosed in 9 patients $(15.0 \pm 4.6 \%)$ of the $1^{\text {st }}$ group and in 10 patients $(12.8 \pm 3.8 \%)$ of the $2^{\text {nd }}$ group, $\mathrm{p}=0.71$.

Only diseases having been included to the index calculator are taken into account for CCI and CA-CCI calculations $[7,8]$. The mean number of diseases and the mean number of diseases being taken into account for the CCI calculation and CA-CCI level in patients of both groups are presented in Table I.

\section{DISCUSSION}

According to the current guidelines, myocardium revascularization in CCS patients should be followed by efficient management and prevention measures $[9,10]$. Comorbidity may have a negative effect on patient's prognosis due, in particular, to limited possibilities of drug use [1]. Besides, it leads also to worsened quality of life; consequently, the better understanding of concomitant pathology is of great importance for the comprehensive assessment of clinical status of CCS patients following PCI $[1,10]$.

Our study demonstrates that the number of comorbidity diseases in CCS patients having undergone PCI ranged from 3 to 12. It is necessary to take into account the fact the number of patients with 10 or more comorbidity diseases was $28.3 \%$ in the $1^{\text {st }}$ group and $43.6 \%$ in the $2^{\text {nd }}$ one. Such a fact increases the risk of polypharmacy and requires a very attentive approach concerning the drug therapy. We have found arterial hypertension to be the most common comorbidity in our patients, our result being in accordance with the data of other researches. Among patients having been included to the Ukrainian registry of acute myocardial infarction there are $79 \%$ of arterial hypertension cases [11]. The results obtained suggest the necessity to optimize the patient management and monitoring to reach a target level of arterial pressure in all the CCS patients having undergone PCI. Special attention should be paid to the significant spreading of type 2 diabetes mellitus and impaired glucose metabolism. According to current clinical 
Table I. The mean number of diseases, $\mathrm{CCl}$, and $\mathrm{CA}-\mathrm{CCl}$ level in patients with chronic coronary syndromes having undergone percutaneous coronary interventions

\begin{tabular}{|c|c|c|c|}
\hline Indices & $1^{\text {st }}$ group $(n=60)$ & $2^{\text {nd }}$ group $(n=78)$ & $\mathbf{p}$ \\
\hline Number of diseases (Mean $\pm m$ ) & $8.2 \pm 0.3$ & $9.3 \pm 0.4$ & NS \\
\hline Number of diseases (Mean $\pm \mathrm{m}$ ) included into the $\mathrm{CCl}$ calculation & $3.8 \pm 0.1$ & $3.9 \pm 0.2$ & NS \\
\hline $\mathrm{CCl}$ & $4.2 \pm 0.2$ & $4.3 \pm 0.2$ & NS \\
\hline $\mathrm{CA}-\mathrm{CCl}$ & $7.3 \pm 0.3$ & $7.5 \pm 0.2$ & NS \\
\hline
\end{tabular}

$1^{\text {st }}$ group: patients having undergone $\mathrm{PCl}$ in acute myocardial infarction;

$2^{\text {nd }}$ group: patients having undergone $\mathrm{PCl}$ for stable coronary artery diseases;

CCl: Charlson Comorbidity Index;

CA-CCl: Combined Age Charlson Comorbidity Index.

guidelines, the presence of type 2 diabetes mellitus leads to two-fold increase of cardiovascular events in CCS patients [1]. Because of such circumstances, it is important to implement an interdisciplinary approach to achieve control of essential risk factors; such an approach requires not only an improvement of glycaemic control and monitoring of glycated hemoglobin level, but also the monitoring of arterial pressure and low density lipoprotein cholesterol levels in these patients [1].

Our comparative analysis of comorbidity spreading in patients having undergone PCI detects some unimportant differences: among the $2^{\text {nd }}$ group patients there are significantly more oft diagnoses of cerebrovascular disease, peripheral arterial disease, chronic pancreatitis $(p<0.05)$ - these features which may be due to long-term chronic process course. No significant differences are found between groups concerning other comorbidities. Among a lot of issues needing their resolution, an important one is a problem of standardized approaches aiming a comprehensive evaluation of patient health for persons with multimorbidity and/or comorbidity and a problem of criteria necessary for evaluation of treating intervention efficiency. For multimorbidity evaluation, several standardized approaches have been proposed taking into account not only the presence of disorders, but also their severity and patient's functional condition. The Charlson Comorbidity Index (CCI) is among the most known ones, it is used from 1987. Several CCI modifications have been proposed, in particular, a modification taking into account the alphanumeric code according to the International statistical classification of diseases and related health problems as well as a CCI variant taking into consideration patient's age - Combined Age CCI (CA-CCI) [7]. It is widely used in cases of longitudinal studies to determine multimorbidity in patients being examined. Taking into consideration current achievements in the management of cardiovascular diseases, there are certain limitations concerning CCI informative value for life span prognosis of such patients. In our study no significant difference concerning the CA-CCI value has been found between patient groups (Table I).

Consequently, the results of our studies prove the high spreading of comorbidities among CCS patients having undergone both urgent and planned PCI, this fact being important for disease prognosis and patient management. Such an aspect of this problem is still poorly investigated and is to be solved.

\section{CONCLUSIONS}

Patients with multiple chronic diseases have increasingly become a critical focus for medical staff, and providing effective clinical care for patients with multimorbidity will remain a primary concern for many years to come. Our study demonstrated a significantly high level of comorbidities in CCS patients having undergone PCI. The mean number of diseases in patients of the $1^{\text {st }}$ and $2^{\text {nd }}$ groups was $8.2 \pm 0.3$ and $9.3 \pm 0.4$, respectively, the CA-CCI values were $7.3 \pm 0.3$ and $7.5 \pm 0.2$, respectively $(p>0.05)$. The most prevalent comorbidities were arterial hypertension, cerebrovascular disease, peripheral arterial disease, type 2 diabetes mellitus, and impaired fasting glycaemia. These patients need an interdisciplinary approach to determine the management according to current guidelines aiming to improve outcomes - the decrease of cardiovascular events development and increase of life span.

\section{REFERENCES}

1. Knuuti J, Wijns W, Saraste A et al. 2019 ESC Guidelines for the diagnosis and management of chronic coronary syndromes: The Task Force for the diagnosis and management of chronic coronary syndromes of the European Society of Cardiology (ESC) Eur Heart J. 2019 Aug 31. pii: ehz425. doi: 10.1093/eurheartj/ehz425.

2. Navickas R, Petric V, Feigl A, Seychell M. Multimorbidity: what do we know? What should we do? J Comorbidity. 2016; 6(1): 4-11.

3. Diachuk D, Moroz G, Hidzynska I, Lasytsia T. Multymorbidnist yak klinichna problema [Multimorbidity as a clinical problem] Ukrainian Cardiology Journal. 2019;1:94-104. (In Ukrainian).

4. Forman D, Maurer M, Boyd Cet al. Multimorbidity in Older Adults with Cardiovascular Disease. Am Coll Cardiol. 2018;71(19):2149-2161. doi: 10.1016/j.jacc.2018.03.022

5. Tušek-Bunc K, Petek D. Comorbidities and characteristics of coronary heart disease patients: their impact on health-related quality of life. Health and Quality of Life Outcomes. 2016;14:159. doi.org/10.1186/ s12955-016-0560-1

6. Sachdev M, Sun JL, Tsiatis A et al. The prognostic importance of comorbidity for mortality in patients with stable coronary artery disease. Journal of the American College of Cardiology. 2004; 43:576-582. doi. org/10.1016/j.jacc.2003.10.031 
7. Roffman CE, Buchanan J, Garry T, Allison GT. Charlson Comorbidities Index. Journal of Physiotherapy. 2016; 62:171.

8. Quan H, Sundararajan V, Halfon P. Coding algorithms for defining comorbidities in ICD- 9-CM and ICD-10 administrative data. Med Care. 2005;43(11):1130-9.

9. Neumann FJ, Sousa-Uva M, Ahlsson A, et al.2018ESC/EACTS Guidelines on myocardial revascularization. European Heart Journal. 2019;40,87165. doi:10.1093/eurheartj/ehy394

10. Piepoli MF, Hoes AW , Agewall S et al. 2016 European Guidelines on cardiovascular disease prevention in clinical practice. European heart Journal. 2016; 37:2315-238. doi:10.1093/eurheartj/ehw106

11. Parkhomenko 0M, Lutay Ya M, Danshan N. Ukrainskiy registr ostrogo infarkta miokarda kak fragment Evropeyskogo: kharakteristika bolnykh. organizatsiya meditsinskoy pomoshchi i gospitalnaya terapiya [Ukrainian registry of acute myocardial infarction as a fragment of the European: patient characteristics, organization of medical care and hospital therapy]. Ukrainian medical chronicle. 2011;1:20-24. (In Russian)

Research work "Improvement of prevention, treatment and rehabilitation of patients with arterial hypertension and coronary heart disease with comorbid pathology in outpatient and inpatient settings» (№ 0119U001045), 2019-2021 yrs (State Institution of Science "Research and Practical Center of Preventive and Clinical Medicine" State Administrative Department)

\section{ORCID and contributionship:}

Galina Z. Moroz - 0000-0003-4329-7193 A, D, E, F

Irina M. Hidzynska - 0000-0001-6643-3843 B, C, D

Anatoly M. Kravchenko - 0000-0001-6863-0197 E, F

Tatyana S. Lasytsia - 0000-0003-1971-5084 ${ }^{\text {B,D }}$

Olena O. Dzyzinska - 0000-0002-1884-3175 D, E

\section{Conflic of interest}

There is no conflict of interest.

\section{CORRESPONDING AUTHOR Galina Z. Moroz}

State Institution of Science "Research and Practical Center of Preventive and Clinical Medicine" State Administrative Department, Verkhnia St. 5, 01014, Kyiv, Ukraine

tel: +380688001816

e-mail:moroz_galina@i.ua

Received: 17.01 .2020

Accepted: 05.03 .2020

A - Work concept and design, B - Data collection and analysis, $\mathbf{C}$ - Responsibility for statistical analysis, D-Writing the article, $\mathbf{E}$-Critical review, $\mathbf{F}$ - Final approval of the article 